\title{
DOCÊNCIA, CURRÍCULO, DIDÁTICA, AULA: fantástico arquivo político da diferença
}

\author{
Sandra Mara Corazza \\ Ester Maria Dreher Heuser \\ Silas Borges Monteiro \\ Tal como o sonho, a docência não é um fenômeno acessório ou \\ aleatório, mas um complexo trabalbo psíquico e político, que \\ expressa a realização. \\ (Sandra Mara Corazza, 2019b).
}

A despeito de as especialidades terem se imposto ao longo do desenvolvimento do conhecimento ocidental, como lento e radical desdobramento da maneira aristotélica de fazer filosofia, o fenômeno humano resiste em manter-se atrelado a esse tipo de composição fragmentária e fragmentada, que tão convenientemente expressamos em "grades curriculares" verdadeiras arenas de lutas em que estão em disputa diferença, identidade, tempos, espaços, sentidos, ideais, valores, modos de vidas e de conhecimentos, conteúdos, disciplinas, competências, habilidades, tradições, narrativas, epistemes, doxas etc. Do ponto de vista da situação macropolítica educacional que nos coube viver, subalterna a governos que desprezam a educação como espaçotempo de conservação da tradição e de criação a partir dela, no encontro entre o novo e o velho, pode-se dizer que Didática e Currículo tornaram-se dobras de consensos fascistas, da violência do preconceito sustentado como doxa educacional própria do pensamento dogmático (DELEUZE, 2018). Pensamento este que, de forma rasa, concebe Matemática e Português como as matérias que realmente importam na Educação Básica, assim como não vê importância nas pesquisas em Ciências Humanas, por isso não merecem financiamento. Pensamento que, para existir e se fortalecer, necessita de uma Docência entristecida, cansada e desgastada física, espiritual e socialmente que, ainda assim, labuta, e muito, de forma neutra, no "quadrado" daquela grade que lhe foi designado.

A vontade de potência afirmativa e alegre de educar, apesar desse quadro macropolítico, insiste em resistir à necessidade de entristecer. Ela se recusa a reproduzir igualzinho a Didática e o Currículo que vêm do alto, pois a Docência que é produzida por essa vontade se afirma como inventora de didáticas e currículos (CORAZZA, 2013). Sabe que "[...] não há lugar neutro ou natural no ensino" (DERRIDA, 1990, p. 114) e, por isso, experimenta possibilidades do pensamento. $\mathrm{O}$ faz no cenário próprio da Docência, a Aula: que começa antes dela, assim como termina, se é que termina, depois que seu tempo formal findou. Pois, ao planejar e "dar" Aula, a Docência é agitada pelo acontecimento que implica imortalizar aqueles que conhecemos e amamos, testemunhando por eles e fazendo-lhes justiça (BARTHES, 2005). Isso porque a Docência transmite para o futuro, para os novos que com ela contracenam, conhecimentos e sensações recuperados e preservados da tradição que, graças a suas escolhas, persistem ao tempo.

Mais do que isso, nesse gesto de recuperação e transmissão da tradição, de transmutação do passado, está contido um tipo especial de criação que implica a transgressão dos cânones científicos, artísticos e filosóficos, matérias de partida que são transformadas na Aula pela transcriação operada por cada docente que, com a atenção de um cão que cavouca o seu buraco, 
produz a sua Aula. Trans-mitir/mutar/gredir/criar/formar, ultrapassar, ir além, só se torna possível quando entra no jogo da Aula a imaginação, garantida pelo direito de sonhar constitutivo da Docência, que a faz "[...] ganhar em valência e operância vitais, pois reúne forças encantadas, que existem apesar de seus criadores" (CORAZZA, 2019a, p. 4-5). Se o pensamento se acomodou muito bem a operar o tratamento da experiência humana no dualismo particular-universal, na lógica hierárquica dos saberes, não significa que, necessária e consequentemente, a existência humana, quando interpretada geometricamente, tenha chegado ao cume das possibilidades do pensamento. Nossa suspeita é que este cume sequer existe, pois quando a imaginação força a dinamicidade do pensamento o faz antecipar e instaurar novas realidades, ela "[...] inventa vida nova, inventa mente nova; abre olhos que têm novos tipos de visão" (BACHELARD, 2013, p. 18). Isso vale como gênese de tudo aquilo que chamamos conhecimento - Filosofia, Ciências, Artes (que existem porque primeiro foram imaginadas-sonhadas) - e compõem o Arquivo da Docência, que se forja num encontro tradutório entre Currículo e Didática.

Os artigos que formam esse dossiê são manifestações do desejo docente de escrevler linhas que experimentam escrileituras (escrita que se faz leitura que se faz escrita) a partir do Arquivo da Docência com o qual a Aula é feita. Seus autores não renunciam ao direito próprio dos professores de se orgulharem desse Arquivo como um ato de resistência ao entristecimento que a doxa educacional, o espírito conservador, o consenso fascista, a voz do natural, a violência do preconceito e das "bênçãos" espalhadas pelo poder majoritário querem nos impor. Arquivo este preparado no Currículo, conjurado na Didática, lutado na Aula, reinventado na Existência de uma docência-pesquisadora constituída em meio à multiplicidade da vida.

A montagem de cada artigo foi orientada por um ou mais conceitos do título do dossiê e, de algum modo, responde as questões da súmula-convite para dele participar, a saber: "Na transitoriedade com que produções da Docência são ensaiadas, imaginadas e (re)feitas, quais dizeres se transmutam para realizar o conhecimento para além do estabelecido? Como pensar o entrelaçado cultural da Docência, do Currículo, da Didática e da Aula, no transcorrer do tempo, ante as diversas tentativas de confinamento dos corpos aprendentesensinantes?".

\section{DOCÊNCIA [DOS ESPECTROS]}

O termo espectro, de Jacques Derrida, apresentado em Espectros de Marx, sustenta uma posição de possibilidade do pensamento da não-presença, característica de todo texto, ente ou ser. O que resta (trace) em um texto não é espiritualmente transcendental, nem pleno de corporeidade: "[...] a palavra phantasma, em grego, significa espectro, embora indique indecisão entre [...] o que não é real, nem fictício, o que não é simplesmente indivíduo, nem um personagem, nem um ator [...] ela é decisiva, ele toca a decisão (DERRIDA, 1997, p. 24); o conceito, como força de decisão, se refere mais à potência de cindir do que aterrorizar. A noção de espectro é essa não-presença operatória; embora espectros estejam rondando, é a presença-ausente que interrompe o espaçotempo do movimento, melhor visto no cinema, pois é “"...] arte do fantasma, isto é, ele não é nem imagem nem percepção. Não é como a fotografia ou como a pintura. A voz ao telefone tem também uma aparência fantasmática. É algo que não é nem real nem irreal" (DERRIDA, 2012, p. 362). Fantasmas rondam, assombram, andarilhos caoticamente entregues ao destino: incontroláveis, presenças não vistas, sem imagens, sem "realidade", pura imagética. Fantasmagoria como jogo do duplo real-irreal, assim como o espectro é o jogo da presença-ausência: uma tragédiametáfora. 
Feita a partir de espectros, deve haver outra Docência, não feita por cópia e reprodução do mesmo, como exercício do adoecimento da vontade, presa a uma só forma. Pelo contrário, no caminho inverso da cópia, da imitação, há de se encontrar sendas, tortuosas, de disseminação. $\mathrm{O}$ sentido não está dado. A produção de sentido é efetivada em disseminação. A pedagogia há de ganhar outra conotação, não mais a da codificação simbólica do acúmulo da cultura, das ciências, das artes, da filosofia, da linguagem, mas como produção de sentido.

A potência de uma Docência dos espectros é ser feita com a disposição de pensar e criar a partir da diferença, trazer matérias e formas escolhidas para o ato educativo em uma posição que arrisca descarregar o peso da orientação ou direcionamento do ato pedagógico. O debate põe sob suspeita a "transposição didática" como realização da matéria da filosofia, da arte e da ciência como imagem original, especular, como reprodutibilidade própria dos espelhos, que se submete ao original; docência dos espectros é reino da indecidibilidade. A dependência da origem, que cria um movimento de replicação simplificada do original, colide com o conceito de espectro. A ideia de transposição didática prende-se à história ocidental metafísica, qual seja, de que determinado conteúdo científico deve ser transposto do âmbito do especialista ao do não-especialista. Ao invés da transposição didática, a docência dos espectros pede uma didática como ato tradutório; no lugar da transposição, que seja a tradução, investindo seu empenho em criar modos e sentidos tradutores no ensino:

Tratamos, desse modo, a concepção de didática como um movimento do pensamento, uma direção tradutória dos atos curriculares - por si próprios, transcriadores de elementos artísticos, filosóficos e científicos. Tradução, que implica menos transportar ou transpor [...] os sentidos de uma língua para outra e mais verter ou recriar: dotando-se da consistência de romper com o estabelecido; empreendendo novos recomeços; apropriando-se do antigo ou do estrangeiro e tornando-os seus, ao entrecruzá-los com a língua didática e fazer ressoar a sua voz (CORAZZA, 2015, p. 108).

Como convite à tradução, a docência transcria seus conteúdos traduzindo-os, pois abandona a instrução catequética e se abre à cena trágica como oferta dionisíaca ao jogo da indecidibilidade, ao ato de criação, à força da disseminação. Ler e escrever transfiguram-se em um pensar que subverte o platonismo, por “[...] recusar o primado de um original sobre a cópia, de um modelo sobre a imagem." (DELEUZE, 2018, ePub.), cuja docência faz de si mesmo experiência do pensamento, da vida, um estilo.

\section{CURRÍCULO [DESTINERRANTE]}

A tradição ocidental criou metáforas das quais é preciso esforço para delas fugir. A alegoria da caverna de Platão, apresentada em $A$ república, conta a saga da libertação de um escravo das sombras do fundo da caverna que encontra o caminho para o sol da verdade. Esse vérum currícŭlum, que na Grécia arcaica era paideia, encontra no fundamento do seu caminho a ginástica, as letras, a lógica, a música; a Idade Média estabelece o trivium (retórica, gramática e lógica), acrescido pelo quadrivium (aritmética, música, geometria e astronomia), organizado por Carlos Magno, em torno do ano oitocentos, quando inaugura seu Império Romano. A convicção de um curso a ser seguido por todos que almejavam esclarecimento dá ao currícŭlum o tom diretivo do caminho que continua a alegoria platônica do trajeto da obscuridade à iluminação. No entanto, e apesar disso, nesse caminho ele 
[...] corre escorre escorrega

atravessa bordeja resvala espalha

comemora glosa redunda

pula turva perscruta cruza fulgura

desliza enrodilha gira

amplia suspira alegoriza

desbasta desvenda descobre

encruzilhadas atalhos ardis emboscadas (CORAZZA, 2009).

Curso destinerrante; viravoltas de Dedalus; astúcia de Penélope enquanto Odisseu segue errante sua jornada pretensamente vitoriosa; protocolo de ingresso à Casa Verde do Dr. Bacamarte: confinamento do Outro para algemar o que mais aterrorizava em si mesmo. Sim, movimento e:

[...] desarranjo, inclinação, assimetria, ruptura de identidade e de igualdade consigo, deiscência daqui e de lá, disso e daquilo, tensão, pressão, excitação, incitação sem ordem, passagem de um a outro que o revela ter sido outro e não um, contração e atração arquiviva de onde a vida mais tarde poderá nascer nesse mais tarde que se abre, já aberto no mais cedo que nunca se deixa capturar de outra forma senão como mais tarde de um outro mais cedo, ou seja, na distensão do impulso - (NANCY, 2015).

\section{DIDÁTICA [LIVRE]}

O substantivo feminino didática [grego, transliterado, didactique, "a arte de ensinar"] é usado como "arte de transmitir conhecimentos", "técnica de ensinar"; também se refere à "[...] parte da pedagogia que trata dos preceitos científicos que orientam a atividade educativa de modo a tornála mais eficiente" (HOUAISS, 2009). Embora não acadêmico, o uso da palavra aproxima-se significativamente do uso comum que se faz do termo. No alemão, Didaktik [do grego didaktikós, didático]: a) ensino, relativo a ensino ou aprendizagem: didática da matemática; b) teoria da formação educativa, método de ensino; c) tratado, ensaio, apresentação de uma teoria didática

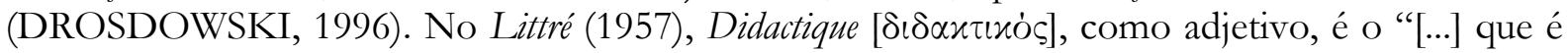
próprio ao ensino, que é usado para instrução". Também se refere a um gênero literário, "o gênero didático", por exemplo: “A Arte Poética de Boileau é um poema didático". Do mesmo modo, é o que pertence a uma ciência, pois se diz "termos didáticos"; por fim, "Didática, a arte de ensinar". A palavra espanhola didáctico, (do grego $\delta \iota \delta \alpha x \tau \iota x o s$ ) é usado como: adjetivo: 1) "pertencente ou relativo ao ensino; 2) próprio, adequado para ensinar ou instruir; método, gênero didático, obra didática; 3) pertencente ou relativo à didática; 4) ao ser usado para pessoas, 'arte de ensinar"' (REAL ACADEMIA, 2014). O Oxford Dictionary of English (STEVENSON, 2010), didact [do grego didaktikos, de didaskein "ensinar"] é adjetivo que "[...] destina-se a ensinar, particularmente em ter instrução moral como um motivo ulterior"; encontra sua primeira ocorrência no século XVII. Em Grande Dicionário da Lingua Portuguesa (TEIXEIRA, 2013), de Portugal, o substantivo feminino "didática" significa "ciência auxiliar da pedagogia", "série de métodos e técnicas" de ensino e "arte e ciência de fazer aprender"; indica que vem do grego didaktiké [tékhne] como "arte do ensino".

Os dicionários Littré e Real Academia Española trazem a palavra grega inscrita, didaktikós. Drosdowski e Oxford transliteram, do mesmo modo, na palavra didaktikós. Com grafias diferentes, os dicionários em língua portuguesa usam a palavra didactique/didaktiké como correlato da palavra grega que funda o termo em português. Esse adjetivo, cujo significado é "apto ao ensino", "próprio para instruir", "didático" ocorre em três textos de toda a literatura grega arcaica e antiga. 
Inicialmente, em duas cartas paulinas enviadas a um cristão de nome Timóteo e em Contra os éticos, de Sexto Empírico. Na primeira carta a Timóteo se encontra escrito:

(1) Eis uma coisa certa: quem aspira ao episcopado, saiba que está desejando uma função sublime. (2) Porque o bispo tem o dever de ser irrepreensível, casado uma só vez, sóbrio, prudente, regrado no seu proceder, hospitaleiro, capaz de ensinar [didaktikon]. [...] [7] Importa, outrossim, que goze de boa consideração por parte dos de fora, para que não se exponha ao desprezo e caia assim nas ciladas diabólicas (BÍBLIA, 2018a, Timóteo I, livro 3, \$1-7).

Esforço algum é feito para ler nessa lista de recomendações eminentemente morais que a didática seja considerada uma entre outras ordenações moralistas; reforçada na segunda carta:

Não convém a um servo do Senhor altercar; bem ao contrário, seja ele condescendente com todos, capaz de ensinar [didaktikón], paciente em suportar os males. [25] É com brandura que deve corrigir os adversários, na esperança de que Deus lhe conceda o arrependimento e o conhecimento da verdade, [26] e voltem a si, uma vez livres dos laços do demônio, que os mantém cativos e submetidos aos seus caprichos (BÍBLIA, 2018b, Timóteo II, livro 2, \$22-26).

Estas cartas paulinas que adversam contra as "paixões da mocidade", em ambas ameaçam o risco de sucumbir às "ciladas diabólicas" ou "laços do demônio"; entre todas as imposições da moral paulina, está a de ser "capaz de ensinar" [didaktikón]. A terceira referência, no caso, não cristã, vem do médico cético Sexto Empírico em sua adversão aos éticos:

Além disso, se o homem sensato ensina o insensato, a sabedoria deve estar ciente da falta de sabedoria, assim como a arte da não-arte. Mas a sensatez não pode estar ciente da insensatez; portanto, o homem sensato não está apto-ao-ensino [didaktikós] dos insensatos (SEXTUS EMPIRICUS, 1936, p. 504-505, \$248).

O cruzamento criado entre Sexto Empírico e São Paulo não deixa de ser curioso, pois o apóstolo de última hora recomenda a um líder de uma comunidade cristã o que, com boa vontade, poderíamos chamar de sensatez; para Sexto Empírico, a sensatez não ensina ao insensato; logo, quem é sensato não é "capaz de ensinar". Porém, esse termo de tão pouca ocorrência na literatura grega arcaica ou clássica é justamente aquele que os dicionários contemporâneos dizem estar vinculado à "arte de ensinar", à didática. Nos parece que esse ideário cristão moralista funda uma noção de didática que insiste em abandonar a "capacidade de ensinar"; ademais, ante a ameaça apostólica dos laços diabólicos aos que se opõem aos preceitos morais listados, entre eles, a "aptidão ao ensino", o que se faz é ensaiar uma resposta que não adjetive a didática - como compreendia até o momento - que dispense sua aura fundante espiritualizada, como vocação, boa conduta, exemplo de retidão para desenhar uma substância informe que seja verbo [didáskô] cuja ação é remunerável [dídaktron], exercida como instituição [didaskaleîon] pela pessoa [didáskalos: professor] que manuseia o ensino [didaskalia] pelo trato de uma lição [didaskálion]. Por opor-se à didática dos modos cristãos [didaktikós], essa didática não vê no laço demoníaco [diabólon] um cativeiro, mas sua libertação, como escreve Corazza (2002, p. 31): "Liberta-se do culto à totalidade, transcendência, dialética, metafísica, humanismo, bem como dos casais de tensões certo/errado, culpa/ castigo, bem/mal, morte/vida. Foge do pensamento único para tornar as singularidades possíveis, afirmar o múltiplo, multiplicar os devires"; que se sabe não apto-ao-ensino, nãovocacionado, embora insista em fazer Aula por experimentação; que compreende que a substância é um nome que deu a si e não uma naturez̧a. 


\section{AULA [CHEIA]}

O substantivo aula é a transliteração do latim aula e do grego aulê. Na Grécia arcaica o termo era usado para designar um pátio ou uma área livre, um jardim, por exemplo, espaço anterior ao prédio principal da casa. Homero, em seu Odisséia chama de aulê a área aberta da entrada do palácio de Alcínoo (HOMER, 1919, p. 242-243); Strabo (1917, p. 4-5), em seu Geografia, usa a palavra para se referir à caverna de Böos Aulê, algo como um "estábulo". O latim aula acompanha o sentido grego, como no poeta latino Modetinus, em seu Cupido adormecido; escreve, assim, sobre o amor jovem: "Em torno dele vieram fantasmas, do salão sombrio de Plutão" (MODESTIUS, 1934, p. 540). Na literatura antiga, grega e romana, o termo designa, por um lado, o espaço antecedente, a céu aberto, ou coberto como uma caverna ou gruta; nessa cavidade aberta entram animais, ou circulam fantasmas.

A Idade Média recupera o sentido greco-latino fundindo-o como salão, espaço de uso, mas com a diferença de que incorpora para sua estrutura identitária a porta. Não há aula sem porta, na Idade Média. O cronista William de Poitiers registra que no Château de Brionne, que em 1047 já era propriedade de Duke William, havia um salão de pedra, ou aula lapidec; no Château Domfort, que em 1051 era de propriedade de Guillaume II Talvas, parece ter havido uma sala (aula) para recepção (GRAVETT, HOOK, 2012). Assim, aula era arquitetura nobre.

Walker (1806) em seu Oxoniana, afirma que em consequência do grande incêndio ocorrido em Oxford, no ano de 1190, a cidade foi reconstruída com o uso de pedra (stone); essa palavra inglesa foi usada para diferenciar as novas habitações populares, como resposta ao incêndio, da arquitetura dos castelos, como Aula Lapidece (salão de pedra) e Aula Tegulata (salão com telhado). No início do século XIX, os salões acadêmicos de Oxford eram ocupados por seus catedráticos, chamados, genericamente, de Aula Regis, algo como um espaço acadêmico de grande importância.

Foi a expansão da construção de prédios destinados à educação de pessoas comuns que levou ao uso de uma arquitetura que imitasse as $A$ ula, vistas nas universidades desde a Idade Média. Hodiernamente, o uso da expressão "sala de aula" é redundante, se for tomado como base o uso do termo ao longo da história. Se o sentido do uso nasce como espaço aberto, a aula foi sendo enclausurada arquitetonicamente e, por que não, conceitualmente.

$\mathrm{Na}$ aula sobrevive o paralelepípedo oco, vazado para instalar uma porta, dispositivo de controle do acesso ao seu interior. Uma sala vazia? Uma sala-aula vazia? Ao que se contrapõe Corazza:

É uma ingenuidade o professor pensar que, ao dar uma aula, está diante de um quadro vazio, de uma página em branco, de uma tela virgem. É um equívoco o professor acreditar que, para fazer uma aula, basta ele entrar na sala, fechar a porta, e dar a aula que quiser. É um erro o professor achar que a sua aula é inexistente; e que, ao fazê-la, poderia reproduzir uma aula que já funcionara como modelo exemplar. O verdadeiro problema do professor não é entrar na aula, mas sair da aula. Isso porque, antes mesmo de começar, a aula já está cheia, e tudo está nela, até o próprio professor. O professor carrega, encontra-se carregado, há cargas: ao seu redor, nos alunos, no plano de ensino, nos livros, na escola. Antes que o professor comece a dar a sua aula, dela pode ser dito tudo, menos que se trata de "a sua aula"; pois a aula está cheia, atual ou virtualmente, de dados; os quais levam o professor a dar uma aula que já está dada, antes que ele a dê (CORAZZA, 2012, p. 23). 


\section{ARQUIVO [FANTÁSTICO]}

Gilles Deleuze (2005, p. 13) abre seu Foucault com a afirmação: "Um novo arquivista foi nomeado na cidade. Mas será que foi mesmo nomeado? Ou, agiria ele por sua própria conta?” Há arquivistas nomeados, que não agem por conta própria? O sueco Caspar Frederik Wegener (18021893) era um arquivista que não dispunha de conta própria; sim, era arquivista (arkivman), mas veio a ser geheimearkivarie, um arquivista do rei que cuidava dos papéis que não podiam ser circulados, nomeação que saiu em 1848; era um arquivista-secreto (geheimearkivarie) por ter a confiança do rei de que o arquivo real seria mantido distante das mãos e olhos não autorizados pela realeza. Wegener guardava segredos. A palavra portuguesa tem vínculo com o latim sécrètum, que se referia a uma coisa escondida, um mistério. Mas em português, a palavra latina também tem proximidade com a palavra secretário, que se distanciou muito da designação da pessoa que guarda segredos. Talvez o ambiente cristão tenha dado ao padre, e não ao secretário, a função de guardar segredos. $\mathrm{Na}$ ilustração citada, Wegener era arquivista-secreto, pois transformava segredos em arquivo.

Derrida, em entrevista a Maurizio Ferraris, respondeu: "Tenho gosto pelo segredo, claramente, isso tem a ver com não-pertencimento"; o receio, ou acanhamento, do espaço público, a hiper exposição midiática, a gana por tudo saber, a pretensa transparência, esse ambiente que o leva a pensar que "[...] se o direito ao segredo não for mantido, estamos em um espaço totalitário" (DERRIDA, 2002, p. 59).

Este vínculo contingente, arquivo-segredo, pode dar a pensar nas figurações metafísicas que se empenham em tornar transparente todo arquivo, todo texto. A Docência, quando trabalha com o arquivo de uma matéria, se arrisca a agir não por conta própria, pois quer desvelar o arquivo das matérias escolares para fazer a "transposição didática" - nome do arquivista que age não por conta própria, que cria um arquivo que não é seu, que se vê possuído por Hermes.

O novo arquivista que chega à cidade, por agir por conta própria, faz tradução transcriadora a fim de realizar a Docência, como Corazza (2019b, p. 10) enuncia:

Endividado, pelo fato de ser herdeiro do arquivo docente; obrigado por um dever tradutório, diante da matéria; culpado por não restaurar o original na íntegra; [...] o professor acaba virando um agente da transmutação de criações, levando o seu espírito de intérprete a substituir o espírito do autor do original. Contudo, a dívida de traduzir e de a-traduzir não deve ser entendida como uma ordem moral da herança.

Não é de ordem moral que se trata, mas de direito à herança, a qual, por direito dos seus herdeiros, cabe à Docência transcriar arquivos didáticos e curriculares - dos quais somos arcontes, guardiões e traidores (CORAZZA, 2019a). Direito exercido sob a condição de uma docência artista, efetivada num tempo trabalhado de artistagem, que promove minoração e disfarce, duplicidade literária, tela pintada de logros, passos em falso, alucinação de um pensamento que pode ser inconsistente, embora não esteja em desacordo com a realidade. Sonho assegurado como ficção forjada entre aqueles que não estão mais cá e os que ainda cá estão.

É graças a este sonho que nós professores, autores deste Dossiê, afirmamos nossa posição de "[...] sujeitos de letras, autores, leitores, tradutores e poetas-pensantes" (CORAZZA, 2019b) que, por nossa dedicação à docência-pesquisa, levamos a matéria original a sobreviver em sua própria língua e atravessar os tempos, conforme são atualizadas, reinventadas e recompostas em Aula. É disso que se trata! 


\section{REFERENCIAS}

BACHELARD, Gaston. A água e os sonhos: ensaio sobre a imaginação da matéria. Tradução de Antonio de Pádua Danesi. São Paulo: WMF Martins Fontes, 2013.

BARTHES, Roland. A preparação do romance I: da vida à obra. Notas de cursos e seminários no Collège de France, 1978-1979. Tradução de Leyla Perrone-Moisés. São Paulo: Martins Fontes, 2005.

BÍBLIA, N. T. Timóteo I. In: BÍBLIA. Sagrada Bíblia. Tradução: Monges Beneditinos de Maredsous. 4. ed. São Paulo: Editora Ave Maria, 2018a. ePub.

BÍBLIA, N. T. Timóteo II. In: BÍBLIA. Sagrada Bíblia. Tradução: Monges Beneditinos de Maredsous. 4. ed. São Paulo: Editora Ave Maria, 2018b. ePub.

CORAZZA, Sandra Mara. Os cantos de Fouror: escrileitura em filosofia-educação. Porto Alegre: Sulina, 2008. (Coleção Cartografias).

CORAZZA, Sandra Mara. Currículo. In: AQUINO, Julio Groppa; CORAZZA, Sandra Mara (orgs.). Abecedário: educação da diferença. São Paulo: Papirus, 2009, p. 40-46.

CORAZZA, Sandra Mara. Didaticário de criação: aula cheia. Porto Alegre: UFRGS, 2012. 202p. (Escrileituras. Cadernos de notas 3)

CORAZZA, Sandra Mara. O que se transcria em educação? Porto Alegre: UFRGS, 2013.

CORAZZA, Sandra Mara. O direito à poética na aula: sonhos de tinta. Revista Brasileira de Educação, v. 24, 2019a.

CORAZZA, Sandra. A-traduzir o arquivo da docência em aula: sonho didático e poesia curricular. Educação em Revista, v. 35, n. e217851, p. 1-25, 2019b.

DELEUZE, Gilles. Foucault. Tradução Claudia Sant'Anna Martins. São Paulo: Ed. Brasiliense, 2005.

DELEUZE, Gilles. Diferença e repetição. Tradução de Roberto Machado e Luiz Orlandi. Rio de Janeiro / São Paulo: Paz \& Terra, 2018. ePub.

DERRIDA, Jacques. Aporías: morir-esperarse (en) los "límites de la verdad". Tradução Cristina de Peretti. Barcelona, Buenos Aires, México: Paidós, 1998.

DERRIDA, Jacques. Du droit à la philosophie. Collection La Philosophie en effet. Paris: Galilée, 1990.

DERRIDA, Jacques; FERRARIS, Maurizio. A taste for the secret. Tradução Giacomo Donis. Malden: Blackwell Publishers, 2002.

DROSDOWSKI, Günther. Duden. Deutsches Universalwörterbuch A-Z. Mannheim: Dudenverlag, 1996.

GRAVETT, Christopher; HOOK, Adam. Norman Stone Castles (2): Europe 950-1204. Oxford: Bloomsbury Publishing, 2012.

HOMER. Odyssey, Volume I: Books 1-12. Tradução de A. T. Murray. Cambridge: Harvard University Press, 1919. [Loeb Classical Library \#104].

HOUAISS, Antonio. Dicionário Honaiss da língua portuguesa. São Paulo: Objetiva, 2009.

LITTRÉ, Émile. Dictionnaire de la langue française. Paris: Jean-Jacques Pauvert/ Gallimard / Hachette, 1957.

LOPES, Alice Casimiro; MACEDO, Elizabeth. Teorias de currículo. São Paulo: Cortez, 2011. 
MODESTINUS. Cupid Asleep. In: Avianus, Hadrian, Florus, Nemesianus, Reposianus, Tiberianus, Phoenix, Rutilius Namatianus. Minor Latin Poets, Volume II: Florus. Hadrian. Nemesianus. Reposianus. Tiberianus. Dicta Catonis. Phoenix. Avianus. Rutilius Namatianus. Others. Tradução de J. Wight Duff, Arnold M. Duff. Cambridge: Harvard University Press, 1934 [Loeb Classical Library \#434].

NANCY, Jean-Luc. Arquivida: do senciente e do sentido. Tradução de Marcela Vieira; Maria Paula Gurgel Ribeiro. São Paulo: Iluminuras, 2015.

REAL ACADEMIA ESPAÑOLA (RAE). Diccionario de la Lengua Espanola RAE. Madrid: Planeta Publishing Corporation, 2014, ePub.

SEXTUS EMPIRICUS. Against Physicists. Against Ethicists. Translated by R. G. Bury. Loeb Classical Library 311. Cambridge, MA: Harvard University Press, 1936.

STEVENSON, Angus. Oxford Dictionary of English. Oxford Dictionary of English. Oxford: Oxford University Press, 2010.

STRABO. Geography, Volume I: Books 1-2. Tradução Horace Leonard Jones. Cambridge: Harvard University Press, 1917. [Loeb Classical Library \#49].

TEIXEIRA, Graciete. Grande Dicionário da Lingua Portuguesa. Porto: Porto Editora, 2013. ePub.

WALKER, John. Oxoniana: Or Anecdotes Relative to the University and City of Oxford. Oxford: Slatter \& Munday, 1806.

\section{Informações dos autores}

Sandra Mara Corazza

UFRGS - Universidade Federal do Rio Grande do Sul, FACED

E-mail:sandracorazza@terra.com.br

ORCID: https://orcid.org/0000-0002-1237-198X

Link Lattes: http://lattes.cnpq.br/5125809962363078

Ester Maria Dreher Heuser

UNIOESTE - Universidade Estadual do Oeste do Paraná, Campus Toledo

E-mail: esterheu@hotmail.com

ORCID: http://orcid.org/0000-0002-1762-7526

Link Lattes: http://lattes.cnpq.br/5548908138476554

Silas Borges Monteiro

UFMT - Universidade Federal de Mato Grosso

E-mail: silasmonteiro@ufmt.br

ORCID: https://orcid.org/0000-0002-6130-920X

Link Lattes: http://lattes.cnpq.br/1235153651563231 